\title{
Femoral sulkus açısı ve patellar subluksasyon ilişkisi
}

\section{The relation between femoral sulcus angle and patellar subluxation}

\author{
Dilek Şen Dokumacl ${ }^{1}$, Sunay Sibel Karayol ${ }^{1}$ (D) \\ 1 Harran Üniversitesi Tıp fakültesi, Radyoloji Anabilim Dalı, Şanlıurfa, Türkiye
}

Öz.

Amaç: Bu çalışmada Diz MR tetkikleri retrospektif olarak incelenerek patellar subluksasyon saptanan hastalarda femur troklear açı ölçümünü kullanarak patellar subluksasyon ile troklear açı arasında ilişki olup olmadığı amaçlandı. Materyal ve Metot: Diz ağrısı şikâyeti ile Radyoloji kliniğinde Diz MR tetkiki yapılan 550 hasta retrospektif olarak PACS sistemi üzerinden değerlendirildi. Bu değerlendirmede patellar subluksasyon varlığı incelendi ve aksiyal planda troklear açı ölçümleri gerçekleştirildi. Patellar subluksasyon patellanın medial veya lateral köşelerinin en rahat görülebildiği aksiyal kesit seçilerek patellanın medial veya lateral köselerine dik olarak çizilen hat ile medial veya lateral femoral kondilin anterior kesimine dik olarak çizilen hat arası mesafenin $5 \mathrm{~mm}$ nin üzerinde olması olarak belirlendi. Troklear açı ise troklear oluğun en derin olduğu kesit seçilerek troklea medial ve lateral fasetlerinin en yüksek noktası ile interkondiler sulkusun en derin noktası arasındaki açı olarak ölçüldü. Patellar subluksasyonu olmayan hastalar kontrol grubu olarak kabul edildi. Patellar subluksasyon saptanan grup ile kontrol grubu troklear açı yönünden karşılaştırılı.

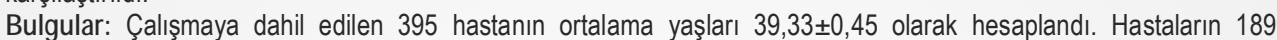
$(\% 47,8)$ )'i kadın, 206 (\%52,2)'si erkek idi. Tüm hastalar birlikte değerlendirildiğinde troklear açı ortalama 132,52 $\pm 0,52$ olarak hesaplandı. Patellar subluksasyon saptanmayan hastalardaki troklear açı ortalama 130,11 $\pm 8,4$ olarak

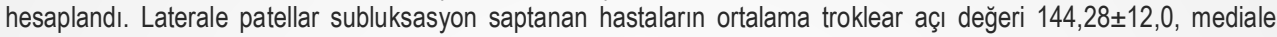
patellar subluksasyonu olan hastaların ortalama troklear açı değeri 133,31 $\pm 10,1$ olarak bulundu. Kontol grubu ile laterale luksasyonu olan grup arasında ise troklear açı yönünden istatistiksel olarak anlamlı farklılık bulundu $(p=0,000)$. Sonuç: Rutin MR incelemelerinde kolaylıkla tanınabilen lateral patellar subluksasyon ile troklear açı arasında anlamlı bir ilişki olup bu patolojinin erken tanısı ve etkili tedavi edilmesi sonucu hastalardaki morbiditenin azalmasına yardımcı olabilir.

Anahtar Kelimeler: Femoral sulkus açısı, Patella, Subluksasyon, Troklear displazi

\section{Abstract}

Background: In this study, we aimed to determine whether there is a relationship between patellar subluxation and trochlear angle by using femoral trochlear angle measurement in patients with patellar subluxation who were evaluated for knee MRI.

Methods: 550 patients with knee pain who underwent knee MRI in the radiology clinic were evaluated retrospectively via PACS system. In this evaluation, the presence of patellar subluxation was examined, and trochlear angle measurements were performed on the axial plane. Patellar subluxation was measured on the axial section where the medial or lateral corners of the patella were easily seen. The distance between the line drawn perpendicular to the medial or lateral corners of the patella and the line drawn perpendicular to the anterior section of the medial and lateral femoral condyles was measured. It was considered as subluxation when this distance was above $5 \mathrm{~mm}$. Trochlear angle was measured as the angle between the highest point of the medial and lateral facets of the trochlea and the deepest point of the intercondylar sulcus. Patients without patellar subluxation were accepted as the control group. Patellar subluxation group and control group were compared in terms of trochlear angle.

Results: Total of 395 patients included in the study. The mean age of them was $39,33 \pm 0,45.189(47,8 \%)$ of the patients were female and $206(52,2 \%)$ were male. When all patients were evaluated together, the mean trochlear angle was calculated as $132,52 \pm 0,52$. The mean trochlear angle was $130,11 \pm 8,4$ in patients without patellar subluxation. The mean trochlear angle of the patients with lateral patellar subluxation was $144,28 \pm 12,0$. The mean trochlear angle of the patients with medial patellar subluxation was $133,31 \pm 10,1$. A statistically significant difference was found between the control group and the lateral patellar luxation group in terms of trochlear angle $(p=0.000)$.

Conclusions: There is a significant relationship between the lateral patellar subluxation and trochlear angle which is an easily recognizable pathology on routine MRI. Early diagnosis and effective treatment of this pathology may help to reduce morbidity.

Keywords: Femoral sulcus angle, Patella, Subluxation, Trochlear dysplasia

\section{Sorumlu Yazar I Corresponding Author}

Dr. Dilek Şen Dokumacı

Harran Üniversitesi Tıp Fakültesi, Radyoloji Anabilim Dalı Şanlıurfa-Mardin Otoyolu 18.Km Şanlıurfa/TÜRKIYE

Tel: +90 4143444161

e-mail: dileksendokumaci@yahoo.com

Geliş tarihi / Received: 22.06.2019

Kabul tarihi / Accepted: 23.07.2019

Bu çalışma, bir ön çalışma şeklinde 'V. Ulusal Harran Ortopedi Günleri' sempozyumunda 6-7 Nisan 2018 tarihleri arasında Şanlıurfa'da sözlü bildiri olarak sunulmuştur.

DOI: 10.35440/hutfd.581297 


\section{Giriş}

Patellar subluksasyon, patellar dislokasyon ile birlikte patellar instabilitenin bir komponentidir. Patellar subluksasyonda patellanın troklear oluğun dışına laterale ya da mediale doğru parsiyel hareketi mevcut olmakla birlikte dislokasyondan farklı olarak troklea ile patellanın eklem ilişkisi devam etmektedir (1). Troklear sulkus açısındaki artışların patellofemoral eklemde osteoartrit gelişimi ile ilişkili olduğunu gösteren çalışmalar vardır (2). Troklea morfolojisinin patellar instabilite gelişiminde de önemli rol oynadığı birçok çalışma ile gösterilmiştir (3). Patellofemoral instabiliteden sorumlu en önemli faktör troklear displazidir (4). Troklear displazi troklear oluğun şekil ve derinliğindeki anormallik olarak tanımlanır. Troklear displazi tanısında ve sınıflandırılmasında klinik ve radyolojik birçok parametre kullanılmaktadır. Günümüzde tanı ve sınıflandırma için en yaygın kullanılan Dejour ve Le Coultre tarafindan yapılan sınıflandırmadır (5). Bu sınıflamaya göre A tipi displazide troklear oluk açısı $145^{\circ}$ 'den daha fazladır. B tipinde troklea düz şekildedir. $C$ tipi displazide trokleanın lateral bölümünde konveksite mevcuttur. $D$ tipi displazide ise trokleanın medial ve lateral yüzleri arasında tümsek bulunmaktadır. Troklear morfoloji ve patella arasındaki ilişkiyi araştıran birçok çaIışma bulunmaktadır $(6,7,8)$. Literatürde patellar instabilitenin bir komponenti olan patellar subluksasyon ile troklear açı arasındaki ilişkiyi değerlendiren bir çalışmaya rastlayamadık.

Bu çalışmanın amacı MR incelemesinde patellar subluksasyon saptanan hastaların troklea morfolojilerinin troklear açı ölçümünü kullanarak değerlendirilmesi ve patellar subluksasyon varlığında troklear açının öneminin olup olmadığının belirlenmesidir.

\section{Materyal ve Metot}

Diz ağrısı şikayeti ile Haziran 2017 ile Haziran 2018 tarihleri arasında Radyoloji kliniğinde diz MR tetkiki yapılan 550 hasta retrospektif olarak PACS sistemi üzerinden değerlendirildi. Çalışmaya 18 yaşının üzerinde olan yetişkin hastalar dahil edildi. Operasyon hikayesi olan, major travma ve/veya patellar dislokasyon öyküsü bulunan, diz ekleminde evre 2, 3, 4 osteoartrit bulguları olan ya da meniskal yırtığı olan hastalar çalışma dışı bırakıldı. Belirgin patellar tilti (lateral patellofemoral açı $>20^{\circ}$ ) olan hastalar çalışmaya alınmadı. Toplam 395 hasta ve diz MR'ı çalışmaya dahil edildi. Hastaların yaş, cinsiyet ve klinik öyküleri hastane kayıt sisteminden alınarak kaydedildi.

MR incelemeleri 3-T magnet gücüne sahip MR cihazı (Magnetom Skyra, Siemens Healthcare) ile standart diz koili kullanılarak gerçekleştirildi. Çalışmada kullanılan aksiyel yağ baskıı I2A TSE görüntüler tüm hastalar için aynı parametreler (TR:2890ms, TE:26ms, FA:150, Thk:3mm, NEX:1) kullanılarak elde edildi.

Çalışmaya dahil edilen hastalarda troklear açı, aksiyal T2 ağırlıklı görüntülerde troklear oluğun en derin olduğu kesit seçilerek troklea medial ve lateral fasetlerinin en yüksek noktası ile interkondiler sulkusun en derin noktası arasındaki açı olarak ölçüldü (Şekil 1). Patellar subluksasyon ise aksiyal T2 ağırıklı görüntülerde patellanın medial veya lateral köşelerinin en rahat görülebildiği aksiyal kesit seçilerek patellanın medial veya lateral köşelerine dik olarak çizilen hat ile medial veya lateral femoral kondilin anterior kesimine dik olarak çizilen hat arası mesafenin $5 \mathrm{~mm}$ nin üzerinde olması olarak belirlendi (2) (Şekil 2). Patellar subluksasyonu olmayan hastalar kontrol grubu olarak kabul edildi.

Elde edilen sayısal veriler SPSS 20.0 (SPSS Inc., Chicago IL, USA) versiyonuna yüklenerek istatistiksel analizler bu program ile değerlendirildi. One-Sample KolmogorovSmirnov testi ile normal dağılım gösterdiği saptanan sayısal verilerin ikili grup karşılaştırmaları için Student-t testi kullanıldı. Üç veya daha fazla grup varlı̆ı̆ında One Way ANOVA testi karşılaştırma için kullanıldı. Grup içi karşılaştırma için post HOC LSD kullanıldı. Verilerin yaş ve cinsiyet açııından dağı ımı Ki-Kare testi ile değerlendirildi. p $<0.05$ değeri istatistiksel olarak anlamlı kabul edildi.

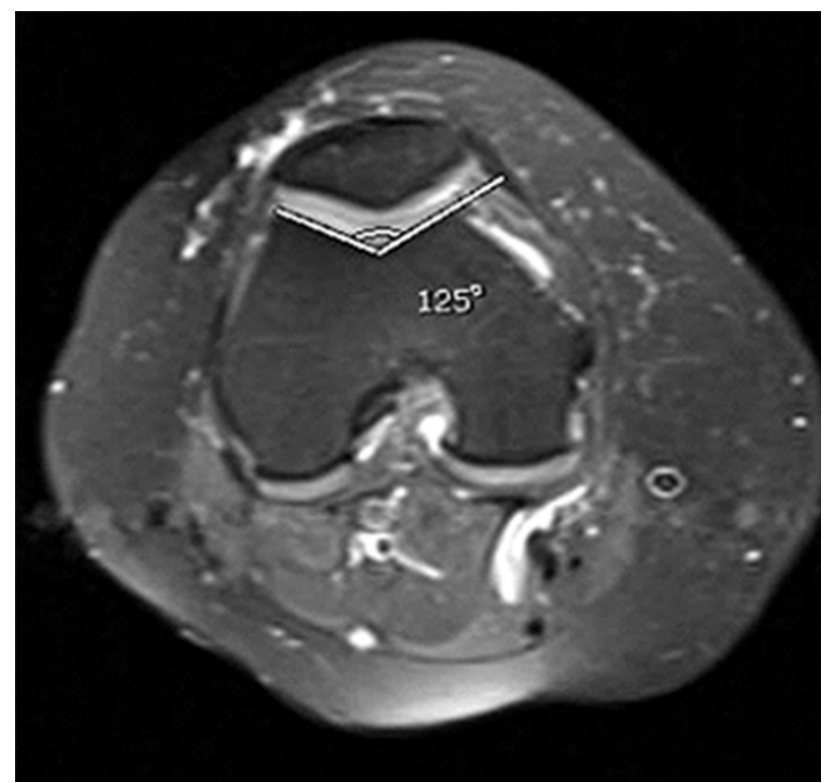

Şekil 1. Aksiyal T2 ağılıklı kesitte troklear oluğun en derin olduğu kesit seçilerek troklea medial ve lateral fasetlerinin en yüksek noktası ile interkondiler sulkusun en derin noktası arasındaki açı ölçümü troklear açı olarak belirlendi.

\section{Bulgular}

Çalışmaya dahil edilen 395 hastanın ortalama yaşları 39,33 $\pm 0,45$ (min-max:21-63) olarak hesaplandı. Hastaların 189 (\%47,8)'i kadın, 206 (\%52,2)'si erkek idi. Her iki cinsiyet arasında yaş farkı bulunmadı $(p=0,222)$. Tüm hastalar birlikte değerlendirildiğinde troklear açı ortalama 132,52 $\pm 0,52$ (min-max:106,0-174,0) olarak hesaplandı. Erkeklerde ortalama troklear açı 132,40 $\pm 9,8$, kadınlarda ortalama troklear açı $132,66 \pm 11,1$ idi. Her iki cinsiyet arasında troklear açı yönünden farkılıı bulunmadı $(p=0.803)$. 
Tüm hastaların $303(\% 76,7)$ 'ünde patellar subluksasyon saptanmadı. Hastaların $60(\% 15,2)$ 'Inda laterale, 32 $(\% 8,1)$ 'sinde mediale subluksasyon mevcuttu. Laterale subluksasyonu bulunan hastaların ortalama yaşı $38,15 \pm 9,0$; mediale subluksasyonu bulunan hastaların ortalama yaşı $42.41 \pm 9,3$ olarak bulundu. Patellar subluksasyon saptanmayan 303 hastanın ortalama yaşları $39,24 \pm 8,9$ idi. Her üç grup yaşları arasında istatistiksel olarak anlamlı farklılık bulunmadı $(p=0.09)$. Patellar subluksasyon saptanmayan hastalardaki troklear açı ortalama

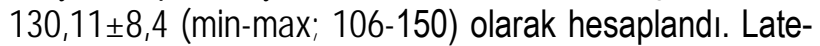
rale patellar subluksasyon saptanan hastaların ortalama troklear açı değeri 144,28 $\pm 12,0$ (min-max;117-174), mediale patellar subluksasyonu olan hastaların ortalama troklear açı değeri 133,31 +10,1(min-max;112-158) olarak bulundu. Luksasyonu olmayan grup ile mediale luksasyon saptanan grup arasında troklear açı yönünden anlamlıya yakın istatistiksel fark saptandı $(p=0.062)$. Luksasyonu olmayan grup ile laterale luksasyonu olan grup arasında ise troklear açı yönünden istatistiksel olarak anlamlı farkllık bulundu $(p=0,000)$. Mediale ve laterale subluksasyonu olan gruplar arasındaki troklear açı değerlerinde de istatistiksel olarak anlamlı farklılık saptandı $(\mathrm{p}=0,000)$.

Troklear açıya göre troklear displazi $48(\% 12,2)$ hastada

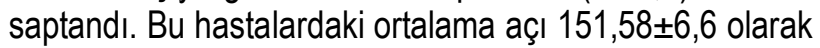
hesaplandı. Troklear dizplazisi olan 48 hastanın 33 tanesinde patellada laterale subluksasyon mevcuttu. Üç hastada ise mediale patellar subluksasyon tespit edildi.

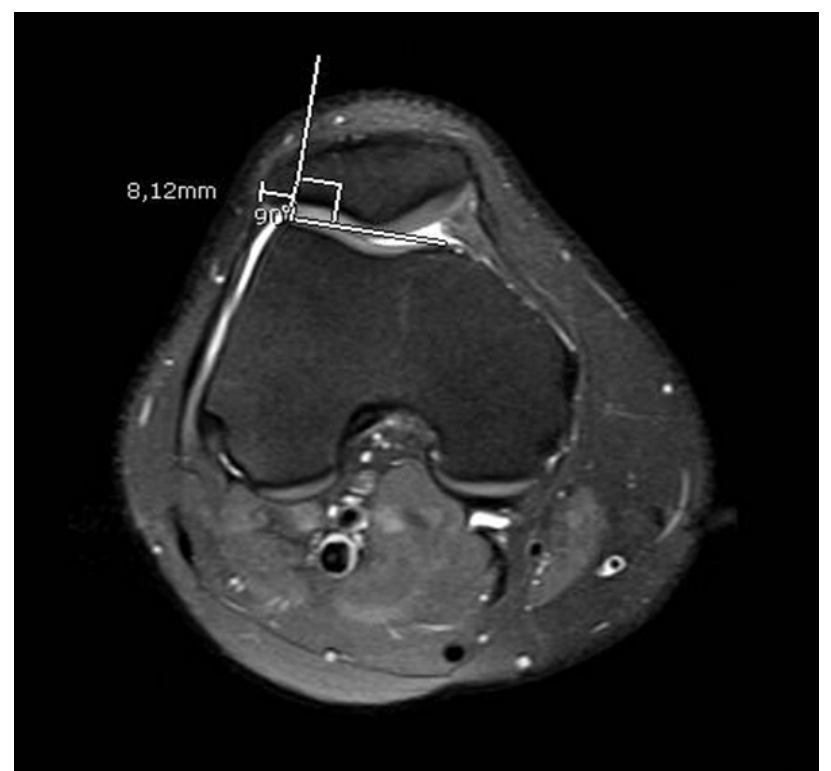

Şekil 2. Aksiyal T2 ağırıklı kesitte patellanın medial veya lateral köşelerinin en rahat görülebildiği bölgede medial veya lateral femoral kondilin anterior kesimine dik olarak çizilen hat ile patellanın medial veya lateral köşelerine dik olarak çizilen hat arası mesafenin $5 \mathrm{~mm}$ nin üzerinde olması patellar subluksasyon olarak tanımlandı.

\section{Tartışma}

Patellar instabilite ile troklear morfoloji arasındaki ilişkinin bilinmesine rağmen bu çalışma ile patellar instabilitenin bir parçası olan patellar subluksasyon ile troklear açının direkt olarak birbiri ile bağlantılı patolojiler olduğu gösterilmektedir. Troklear morfoloji ile kondromalazi patella arasındaki ilişkiyi araştıran bir çalışmada kontrol grubu ile karşılaştırıdığında kondromalazi patella tanısı olan hastalarda troklear sulkus açısının daha geniş olduğunu tespit edilmiştir (7). Aynı çalışmada kontrol grubunda ortalama troklear sulkus açısını $130 \pm 9.2$ derece, kondromalazi patella olan grupta ise troklear sulkus açısını $143.3 \pm 8$ derece olarak belirtmişlerdir. Bu değerler bizim çalışmamızda patellar subluksasyonu olmayan ve olan grupta saptadığımız açı değerleri ile benzerlik göstermektedir. Yi ve ark. (9) yaptıkları çalışmada klinik ve muayene verileri ile patellofemoral instabilite tanısı almıs olan hastaların MR görüntülerini retrospektif olarak incelemiş ve aksiyal ve oblik koronal planlarda değişik seviyelerden troklear sulkus açı ölçümü yapmışlardır. Aksiyal planda aldıkları açı ölçümlerinde troklear oluğu esas almışlar ve troklear oluğu üst, orta ve alt olarak üç bölgeye ayırıp bu bölgelerden açı ölçümü gerçekleştirmişlerdir. Her üç seviyeden aldıkları açı ölçümlerini kontrol grubu ile karşılaştırdıklarında çalışmamızla benzer şekilde üç seviyede de anlamlı farklılık saptamışlar ve instabilite olan grupta troklear açının daha geniş olduğunu belirtmişlerdir. Ancak bu çalışmada patellofemoral instabilite tanısı klinik olarak konmuş olup patellofemoral instabilite nedenleri göz önüne alındığında oldukça geniş bir hasta grubunu kapsamaktadır.

Radyografik olarak patellar subluksasyon saptanan ve patellar dislokasyon öyküsü olan hastalarda patellar kartilaj değişikliklerini inceleyen ve artroskopi ile karşılaştıran bir başka çalışmada hastaların çoğunda patellar kartilajda kaınlık artışı (>5mm), irregularite, ve kartilaj kaybı gibi patolojiler saptanmışlardır (10) Patellar subluksasyonun zaman içerisinde kartilaj patolojilerine neden olması radyolojik ve klinik açıdan erken tanısının oldukça önemli olduğunu göstermektedir. Posterior lateral femoral kondil geometrisinin patellar dislokasyon ve patellar subluksasyon ile ilişkisini araştıran bir çalışmada patellar dislokasyonu veya patellar subluksasyonu olan hastalar tek bir grup şeklinde ele alınmış olup MR görüntüleri retrospektif olarak incelenmiş ve ilginç olarak troklear sulkus açısının hasta grubu ile kontrol grubu karşılaştırıldığında istatistiksel olarak anlamlı farklılık göstermediği saptanmıştır (6). Bu sonuç muhtemelen travmaya sekonder gelişmiş patellar dislokasyon-subluksasyon ile konjenital patellar dislokasyon-subluksasyonu olan hastaların aynı grup içinde değerlendirilmesi nedeniyle ortaya çıkmış olabilir. Ayrıca belirtilen çalışmaya sadece 25 patellar instabiltesi olan hasta dahil edilmiş olup hasta sayısının az olması da çalışma sonucuna etki etmiş olabilir. Tsavalas ve ark. (2) patellofemoral eklem osteoartriti ile troklear sulkus açısının da dahil olduğu birçok parametreyi kontrol grubu ile karşılaşıłırmış ve osteoartrit olan grupta troklear sulkus açısının kontrol grubuna göre anlamlı olarak geniş olduğunu belirtmişlerdir. Bu çalışmada 
50 yaşının altındaki ve üstündeki hasta gruplarında ayrı ayrı osteoartrit derecesi ile troklear sulkus açısının arasında kuvvetli pozitif korelasyon saptamışlardır. Troklear displazide patella morfolojisini araştıran bir başka çalışmada displazi olan grupta patella medial faset uzunluğunun kontrol grubu ile karşılaştırıldığında belirgin azaldığı bulunmuştur. Troklear displazi olan grupta Wiberg sınıflamasına göre tip 2 ve tip 3 patella morfolojisinin daha sık görüldüğü rapor edilmiş ve troklear displazide patella morfolojisinin epigenetik veya genetik faktörlerle belirlenmekte olabileceği yorumu yapılmış̧ır (11).

Geniş troklear sulkus açısı ve patellar subluksasyon varIığı, yumuşak doku ve kemik doku komponentleri ile birlikte kompleks bir yapı olan patellofemoral eklemin mekaniğini olumsuz yönde etkileyen birbiri ile ilişkili faktörler olup kondromalazi patella ve osteoartrit gelişiminden de sorumlu oldukları literatür ışığında söylenebilir.

Çalışmamızın bazı sınırlııkları bulunmaktadır. İlk olarak çalışmamızda patellofemoral eklemi değerlendirmekte önemli parametreler olan patella tipini, troklea tipini, tuberositas tibia-troklear oluk mesafesini dahil etmedik. İkinci olarak patella ve femurun ilişkisi dinamik bir süreci kapsadığı halde biz sadece ekstansiyonda elde edilen MR görüntüleri üzerinden patellar subluksasyon tanısı koyduk.

Sonuç olarak, lateral patellar subluksasyon ile troklear açı arasında direkt bir ilişki mevcut olup rutin MR incelemelerinde kolaylıkla tanınabilen patellar subluksasyonun erken tanısı ve hastaların erken dönemde etkili tedavi edilmesi morbiditenin azalmasına neden olabilir.

\section{Kaynaklar}

1. Parikh SN, Lykissas MG. Classification of Lateral Patellar Instability in Children and Adolescents. Orthop Clin North Am. 2016; 47(1):145-152.

2. Tsavalas $\mathrm{N}$, Katonis $\mathrm{P}$, Karantanas $\mathrm{AH}$. Knee joint anterior malalignment and patellofemoral osteoarthritis: an MRI study. Eur Radiol. 2012; 22(2):418-428.

3. Toms AP, Cahir J, Swift L, Donell ST. Imaging the femoral sulcus with ultrasound, CT, and MRI: reliability and generalizability in patients with patellar instability. Skeletal Radiol. 2009; 38(4):329-38.

4. Parikh SN, Rajdev N. Trochlear Dysplasia and its Relationship to the Anterior Distal Femoral Physis. J Pediatr Orthop. 2019; 39(3):177-184.

5. Dejour D, Le Coultre B. Osteotomies in patello-femoral instabilities. Sports Med Arthrosc Rev. 2007; 15(1):39-46.

6. Gillespie D, Mandziak D, Howie C. Influence of posterior lateral femoral condyle geometry on patellar dislocation. Arch Orthop Trauma Surg. 2015; 135(11):1503-9

7. Duran S, Cavusoglu M, Kocadal O, Sakman B. Association between trochlear morphology and chondromalacia patella: an MRI study. Clin Imaging. 2017; 41:7-10.

8. Tsakoniti AE, Mandalidis DG, Athanasopoulos SI, Stoupis CA. Effect of Q-angle on patellar positioning and thickness of knee articular cartilages. Surg Radiol Anat. 2011; 33(2):97-104.

9. Yi M, Hong SH, Choi JY, Yoo HJ, Kang Y, Park J, et all. Femoral Trochlear Groove Morphometry Assessed on Oblique Coronal MR Images. AJR Am J Roentgenol. 2015; 205(6):1260-8.

10. Nakanishi K, Inoue M, Harada K, Ikezoe J, Murakami T, Nakamura $\mathrm{H}$, et all. Subluxation of the patella: evaluation of patellar articular cartilage with MR imaging. Br J Radiol. 1992; 65(776):662-7.

11. Fucentese SF, von Roll A, Koch PP, Epari DR, Fuchs B, Schottle $\mathrm{PB}$. The patella morphology in trochlear dysplasia--a comparative MRI study. Knee. 2006; 13(2):145-50. 